\title{
Analysis of Patterns of Pineapple Mealybug Wilt Disease in Sri Lanka
}

\author{
G. Hughes and S. Samita, Institute of Ecology and Resource Management, University of Edinburgh, Edinburgh \\ EH9 3JG, Scotland UK
}

\begin{abstract}
Hughes, G., and Samita, S. 1998. Analysis of patterns of pineapple mealybug wilt disease in Sri Lanka. Plant Dis. 82:885-890.

Mealybug wilt disease of pineapple has a complicated etiology, which is not yet fully understood. As a result, assessments of the disease in the field, such as those that are made in the context of evaluation of disease control methods, are usually based on symptomatology. Field assessments, based on symptoms of mealybug wilt disease, were made in the Kurunegala and Gampaha districts of Sri Lanka. These data were fitted to statistical probability distributions as a method of summarizing the spatial pattern of disease incidence. Most plots showed aggregated patterns of diseased plants, but there were some exceptions. Summarizing patterns of disease incidence by means of fitting statistical probability distributions provides a basis for significance testing in cases where factors affecting disease incidence are the subject of field experimentation. Some examples of this methodology are given.
\end{abstract}

Additional keywords: binomial distribution, logistic-normal-binomial distribution

Mealybug wilt disease is a constraint on pineapple productivity in Sri Lanka and other countries in which pineapple (Ananas comosus (L.) Merr.) is cultivated. The etiology of mealybug wilt disease is complicated, and not yet fully understood $(9,26)$. In Sri Lanka (4), as elsewhere $(21,22,24)$, a relationship between mealybugs and the disease has been known for a long time. More recently, the discovery of virus-like particles associated with mealybug wilt (10-13) seemed to point to a viral etiology for the disease. However, despite further work $(16,25-28)$, this still remains to be established $(15,23)$.

Since pineapples are cultivated vegetatively, pineapple viruses are likely to be widespread $(9,25)$. In Hawaii, pineapple closterovirus-like virions are found in asymptomatic pineapple plants (15). In Sri Lanka, enzyme-linked immunosorbent assay (ELISA) methods (based on those described in 19) were used (E. M. Dassanayake, D. L. Wikremasingha, and W. G. S. Perera, unpublished) to distinguish between infected and uninfected pineapple plants. It was found that "most of the plants in the field carry the infection," whether or not disease symptoms were exhibited. This indicates that, at least until a clearer under-

Corresponding author: G. Hughes

E-mail: ghughes@srv0.bio.ed.ac.uk

Current address of second author: Faculty of Agriculture, University of Peradeniya, Peradeniya, Sri Lanka.

Accepted for publication 17 April 1998.

Publication no. D-1998-0601-01R

(C) 1998 The American Phytopathological Society standing of the etiology of mealybug wilt is available, disease assessments in the field (such as those that form part of the experimental evaluation of methods proposed for mealybug wilt disease management) will be based on symptomatology.

At present, pineapple plants are classified as either "healthy" or "diseased," on the basis of an assessment of the visual symptoms of mealybug wilt disease. In the future, if further research on the etiology of mealybug wilt yields a definitive assay, it may be possible to make a similar classification on a more rigorous basis. However, given the systemic nature of mealybug wilt, it seems likely that any forthcoming alternative assessment method will, like the present one, provide incidence data. This article describes an analysis of mealybug wilt disease incidence data collected in field plots in Sri Lanka. The disease incidence data described here were based on visual symptoms of mealybug wilt, but the methodology outlined in this article is appropriate for the statistical analysis of disease incidence data, however incidence is assessed. Thus, the emphasis of the present article is on the description of methods appropriate for the analysis of disease incidence data. In particular, attention is focused on the correspondence between distribution-fitting methods commonly practiced in plant disease epidemiology for analysis of spatial pattern (e.g., 2) and methods for the analysis of disease incidence data of the kind that may be collected from field experiments conducted with a view to pineapple mealybug wilt disease management. Applications of these methods in the temporal analysis of disease, and in the formulation of risk algorithms, are briefly discussed.

\section{MATERIALS AND METHODS}

Data collection. Data on the incidence of mealybug wilt disease were collected in Sri Lanka in late 1993 and early 1994. Pineapple is grown mainly in the Kurunegala and Gampaha districts of Sri Lanka. From each of these two districts, a list was compiled of commercial pineapple plantations from which mealybug wilt disease had been reported to the local extension services. These plantations were grouped by village, and two villages from each district were selected, at random, for data collection. The villages selected were Wariyapola and Kuliyapitiya from the $\mathrm{Ku}-$ runegala District, and Nittambuwa and Attanagalla from the Gampaha District. We present data from four plantations at each village (Table 1).

The plantations for which data are presented have been selected so that the four plantations at each village make up a factorial set of two levels of each of two factors from among those important in pineapple cultivation: year of cultivation (in Sri Lanka, pineapple crops have a commercial life span of 4 years); cultivar; use of pesticides; and use of fertilizer (Table 1). This arrangement will be referred to later, when methodology for analysis of the mealybug wilt disease incidence data in relation to their factor structure is discussed.

In Sri Lanka, pineapples are cultivated in "double rows" (Fig. 1). In established plantations, the double-row layout is hardly distinguishable, and we simply refer to the double rows as "rows." In each plantation, an area comprising 360 plants, arranged in a 12 row $\times 30$ plant array (referred to as a "plot"), was selected, at random, for disease assessment. In each selected array, all plants were assessed on the basis of visual (aboveground) symptoms of mealybug wilt disease and recorded as either healthy (asymptomatic) or diseased (symptomatic). Symptoms of mealybug wilt have been described by, for example, Carter (3) (see also 9,22). Affected pineapple plants show the following sequence of symptoms: reddening of the leaves, inward reflexing of the leaf margins, and loss of leaf rigidity, after which plants usually die. A "recovery state" noted by Carter (3) is rarely observed in Sri Lanka (8). The outcome of the assessment procedure is that the location and disease status of each plant in an array is known. This information can be presented in the form of a "map" of a plot.

Fitting statistical probability distributions. In order to fit statistical probability 
distributions to observed disease incidence data, such as those recorded in the present study, maps of disease incidence can be divided into "quadrats" (5). Field observations, and subsequent study of the prepared maps, suggested that the pattern of mealybug wilt disease incidence was such that there were "runs" of diseased plants along rows. The map for each plot was divided into 36 quadrats, each comprising 1 row $\times$ 10 plants along rows. A frequency distribution of diseased plants per quadrat was then compiled for each map.

If the probability of a plant being infected were equal for all plants, independent of the location and disease status of neighboring plants, the binomial probability distribution might be expected to be a good description of the observed frequency distribution of diseased plants per quadrat
(5). This would be indicative of a random pattern of diseased plants at the withinquadrat spatial scale. In many cases, however, studies of patterns of plant disease incidence have indicated that disease tends to be patchy rather than random (2). In terms of the frequency distribution of diseased plants per quadrat, patchiness (clustering, heterogeneity, aggregation, overdispersion) manifests itself as an excess of observed frequencies over expected binomial frequencies in the tails of the distribution, and a corresponding deficit of observed frequencies in the center. That is to say, when disease is patchy, quadrats tend to have few diseased plants, or many. A number of probability distributions have been suggested as being capable of describing this type of deviation from randomness (1). In the present study, the lo-

Table 1. Villages and plantations from which data were collected

\begin{tabular}{|c|c|c|c|c|}
\hline Plantation & $\begin{array}{c}\text { Year of } \\
\text { cultivation }\end{array}$ & Cultivar & $\begin{array}{l}\text { Pesticide } \\
\text { applied?a }^{\text {a }}\end{array}$ & $\begin{array}{l}\text { Fertilizer } \\
\text { applied? }^{\mathbf{b}}\end{array}$ \\
\hline \multicolumn{5}{|c|}{ District - Kurunegala; Village - Wariyapola } \\
\hline Panduwasnuwara & 1 & Murici & No & No \\
\hline Hettipola & 1 & Murici & No & Yes \\
\hline Kobeigane & 1 & Murici & Yes & No \\
\hline Bingiriya & 1 & Murici & Yes & Yes \\
\hline \multicolumn{5}{|c|}{ District - Kurunegala; Village - Kuliyapitiya } \\
\hline Devasarana & 1 & Murici & No & Yes \\
\hline Munumaldeniya & 4 & Murici & No & Yes \\
\hline Akkarawatta & 1 & Murici & Yes & Yes \\
\hline Mukalanyaya & 4 & Murici & Yes & Yes \\
\hline \multicolumn{5}{|c|}{ District - Gampaha; Village - Nittambuwa } \\
\hline $\mathrm{JEDB}^{\mathrm{c}}$ & 1 & Murici & No & Yes \\
\hline Aluwala & 4 & Murici & No & Yes \\
\hline Walgammana & 1 & Murici & Yes & Yes \\
\hline Welhena & 4 & Murici & Yes & Yes \\
\hline \multicolumn{5}{|c|}{ District - Gampaha; Village - Attanagalla } \\
\hline Kattota & 2 & Murici & Yes & Yes \\
\hline Kalagedihena & 4 & Murici & Yes & Yes \\
\hline Navadiga & 2 & Kew & Yes & Yes \\
\hline Urapola & 4 & Kew & Yes & Yes \\
\hline
\end{tabular}

a At recommended rates (7).

b At recommended rates (7).

${ }^{c}$ A government-owned commercial plantation administered by the Janatha Estate Development Board.

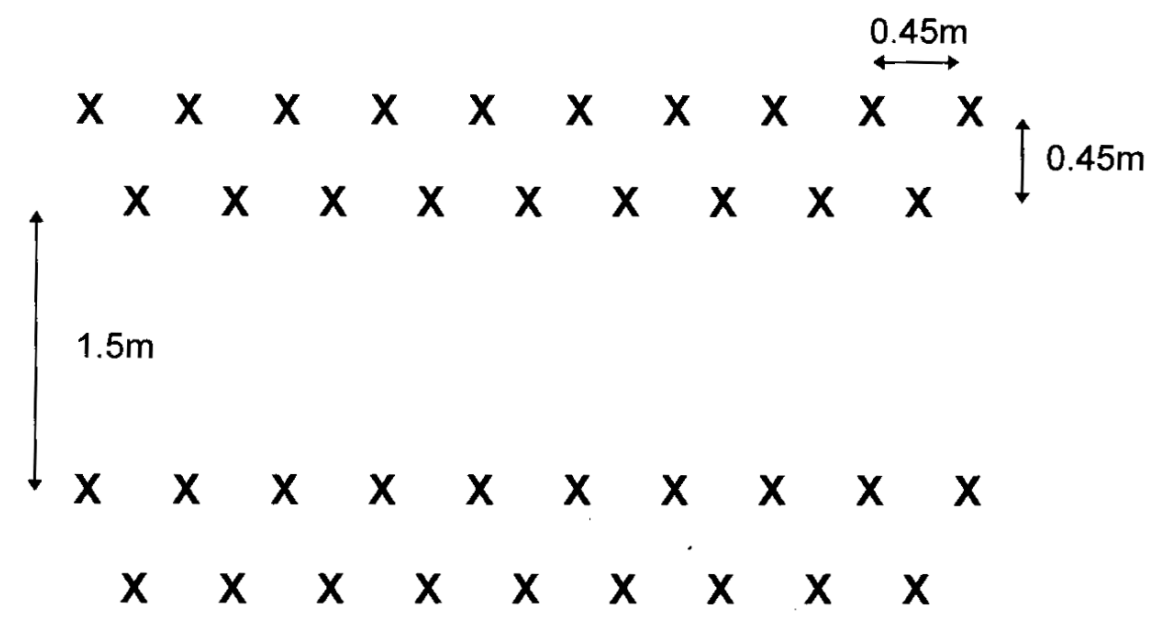

Fig. 1. The "double row" planting pattern of pineapples. Individual plants are marked X. Agronomic rows run horizontally.

gistic-normal-binomial (LNB) distribution was adopted. For a comparative account of the LNB and beta-binomial distributions, see Hughes et al. (17) and the literature cited therein.

Both the binomial and LNB distributions were fitted to the observed frequency distributions of diseased plants per quadrat. Maximum likelihood parameter estimation was carried out using EGRET (version 1.02.10, Cytel Software Corporation, Cambridge, MA); and expected frequencies were calculated using Mathcad (version PLUS 6.0, MathSoft Inc., Cambridge, MA). The fit of the observed distribution to the expected binomial and LNB distributions was then tested by calculation of both $\chi^{2}$ goodness-of-fit tests and likelihood ratio statistics (LRSs). For the $\chi^{2}$ goodness-of-fit tests, a conservative rule for pooling of expected frequencies was adopted. Classes were pooled until expected frequencies of at least 4 were obtained. LRSs were calculated from the difference between the deviances that result from first fitting to the observed data for a plot, the (one-parameter) binomial distribution, then the (two-parameter) LNB distribution.

Analysis of the data according to their factor structure. For continuous, normally distributed data, analysis of variance (ANOVA) provides a basis for the analysis of data that have a factor structure arising from the experimental design. However, this presents some problems for disease incidence data, since data in the form of proportions (being neither continuous nor normally distributed) may fail to satisfy some of the assumptions of ANOVA. Generalized linear models (GLMs) (18) provide a method of analysis that takes account of the properties of disease incidence data. For an overview of the analysis of data that take the form of proportions, such as disease incidence data, see Collett (6).

A GLM approach allows the use of a transformation (link function) to achieve a linear model, together with an explicit specification of an appropriate distribution for the response variable. For proportions, the linear logistic model is often an appropriate starting point, in which case the logit link function and the binomial distribution are specified. To estimate a single parameter (the probability that a plant is diseased, $p$ ) for the data set from a village, we can write:

$$
\operatorname{logit}(p)=\ln \left(\frac{p}{1-p}\right)=C_{0}
$$

In equation 1 , the linear systematic component of the model, given in this case by $\eta=C_{0}$ (a constant), is referred to as the "linear predictor," and its estimated value is denoted $\hat{\eta}$. The logit link relates the linear component to the value of $p$. Whereas $p$ is restricted to values between zero and one, $\operatorname{logit}(p)$ may lie anywhere between $\pm \infty$. 
The probability that a plant is diseased is then estimated by $\hat{p}=\exp [\hat{\eta}] /(1+\exp [\hat{\eta}])$.

For a $2^{2}$ factorial arrangement, the full (or "saturated") linear logistic model is:

$$
\operatorname{logit}\left(p_{i j}\right)=C_{0}+A_{i}+B_{j}+(A B)_{i j}
$$

in which $p_{i j}$ is the probability that a plant exposed to the $i$ th level of factor $A$ and the $j$ th level of factor $B(i=1,2 ; j=1,2)$ is diseased. In equation 2 , the linear predictor is given by $\eta_{i j}=C_{0}+A_{i}+B_{j}+(A B)_{i j}$. Once $\hat{\eta}_{i j}$ has been estimated, $\hat{p}_{i j}=\exp \left[\hat{\eta}_{i j}\right] /(1+$ $\left.\exp \left[\hat{\eta}_{i j}\right]\right)$ can be obtained.

If the value of the residual deviance after fitting the model represented by equation 2 is close to its degrees of freedom (df), this indicates that the binomial distribution provides an acceptable description of within-plot variability. Standard errors of parameter estimates from a linear logistic model provide a valid basis for comparisons of the effects of different levels of factors. One the other hand, a large value for the residual deviance is an indication that the binomial distribution provides an inadequate description of within-plot variability. In such circumstances, the standard errors of parameter estimates from a linear logistic model are artificially small, and so tend to lead to erroneous assessments of statistical significance. One way to overcome this problem is to base the analysis on a distribution such as the LNB, which takes account of excess within-plot variability.

The LNB model is based on the assumption that the $\operatorname{logit}\left(p_{i j}\right)$ values vary about a mean of $\eta_{i j}$, and that the variability can be described by a normal distribution. The simplest LNB model that is an extension of the linear logistic model shown in equation 2 is:

$$
\operatorname{logit}\left(p_{i j}\right)=C_{0}+A_{i}+B_{j}+(A B)_{i j}+\gamma_{0} \cdot z_{i j}
$$

in which the $z_{i j}$ are independently distributed standard normal random variables. Thus $\operatorname{logit}\left(p_{i j}\right)=\eta_{i j}+\gamma_{0} z_{i j}\left(\gamma_{0} \geq 0\right)$. The model represented by equation 3 , which involves a single aggregation parameter, common to all plots, may be extended to include further aggregation parameters, reflecting the factor structure of the data set:

$$
\begin{aligned}
& \operatorname{logit}\left(p_{i j}\right)=C_{0}+A_{i}+B_{j}+(A B)_{i j} \\
& +\left(\gamma_{0}+\gamma_{A i}+\gamma_{B j}+\gamma_{(A B) i j}\right) z_{i j}
\end{aligned}
$$

that is, $\operatorname{logit}\left(p_{i j}\right)=\eta_{i j}+\left(\gamma_{0}+\gamma_{A i}+\gamma_{B j}+\right.$ $\left.\gamma_{(A B) i j}\right) z_{i j}$. Since, in both equations 3 and 4 , the $z_{i j}$ have zero expectation, we can still calculate $\hat{p}_{i j}=\exp \left[\hat{\eta}_{i j}\right] /\left(1+\exp \left[\hat{\eta}_{i j}\right]\right)(6)$.

In the present study, models represented by equations 1 to 4 were (where possible) fitted, sequentially, to the data set for each village. After first fitting the model represented by equation 1, the LRS (reduction in deviance) resulting from each successive fit was calculated. These LRSs were used as a basis for deciding which model best described within-plot variability. Maximum likelihood parameter estimates and their standard errors were then calculated using EGRET.

\section{RESULTS}

Fitting statistical probability distributions. The results of tests of goodness-of- fit on fitting both the binomial and LNB distributions to the observed frequency distributions of diseased plants per quadrat are shown in Table 2. Overall, the tests indicated that the pattern of diseased plants

\begin{tabular}{|c|c|c|c|c|c|c|}
\hline \multirow[b]{2}{*}{ Plantation } & \multicolumn{2}{|c|}{ Binomial distribution } & \multicolumn{2}{|c|}{ LNB distribution } & \multicolumn{2}{|c|}{ Analysis of deviance } \\
\hline & $\chi^{2}(\mathbf{d f})^{\mathrm{a}}$ & $P$ & $\chi^{2}(\mathbf{d f})^{\mathrm{a}}$ & $\boldsymbol{P}$ & LRS (1 df) & $P^{\mathbf{b}}$ \\
\hline \multicolumn{7}{|c|}{ District - Kurunegala; Village - Wariyapola } \\
\hline Panduwasnuwara & $6.42(3)$ & 0.093 & $6.12(2)$ & 0.047 & 0.13 & 0.36 \\
\hline Hettipola & $0.63(2)$ & 0.73 & $0.65(1)$ & 0.42 & 0.003 & 0.48 \\
\hline Kobeigane & $9.63(3)$ & 0.022 & $9.93(2)$ & 0.008 & $\ldots$ & $\ldots$ \\
\hline Bingiriya & $6.88(3)$ & 0.076 & $6.88(2)$ & 0.032 & $\ldots$ & $\ldots$ \\
\hline \multicolumn{7}{|c|}{ District - Kurunegala; Village - Kuliyapitiya } \\
\hline Devasarana & $48.30(2)$ & $<0.001$ & $0.51(1)$ & 0.48 & 90.08 & $<0.001$ \\
\hline Munumaldeniya & $15.10(3)$ & 0.002 & $2.56(2)$ & 0.28 & 20.38 & $<0.001$ \\
\hline Akkarawatta & $16.80(2)$ & $<0.001$ & $2.66(2)$ & 0.26 & 58.90 & $<0.001$ \\
\hline Mukalanyaya & $9.80(2)$ & 0.007 & $4.63(2)$ & 0.10 & 28.21 & $<0.001$ \\
\hline \multicolumn{7}{|c|}{ District - Gampaha; Village - Nittambuwa } \\
\hline JEDB & $4.53(2)$ & 0.10 & $0.84(2)$ & 0.66 & 11.98 & $<0.001$ \\
\hline Aluwala & $4.33(3)$ & 0.23 & $12.70(1)$ & $<0.001$ & 37.16 & $<0.001$ \\
\hline Walgammana & $10.90(2)$ & 0.004 & $0.58(1)$ & 0.47 & 56.80 & $<0.001$ \\
\hline Welhena & $10.80(3)$ & 0.013 & $1.88(3)$ & 0.60 & 23.57 & $<0.001$ \\
\hline \multicolumn{7}{|c|}{ District - Gampaha; Village - Attanagalla } \\
\hline Navadiga & 10.40 & 0.001 & & & 15.40 & $<0.001$ \\
\hline Kattota & $3.99(2)$ & 0.14 & $1.26(2)$ & 0.53 & 16.55 & $<0.001$ \\
\hline Kalagedihena & $21.80(3)$ & $<0.001$ & $2.07(3)$ & 0.56 & 35.15 & $<0.001$ \\
\hline Urapola & $4.35(3)$ & 0.23 & $2.38(2)$ & 0.30 & 4.43 & 0.018 \\
\hline
\end{tabular}
at the within-quadrat scale was aggregated

Table 2. Tests of goodness-of-fit of the binomial and logistic-normal-binomial (LNB) distributions to the observed data from each plantation

${ }^{a} \chi^{2}$ has df equal to the number of frequency classes (after pooling, if necessary) minus one more than the number of estimated parameters for the fitted distribution. Thus, for the binomial parameter, $\mathrm{df}$ $=$ number of frequency classes -2 ; for the $\mathrm{LNB}, \mathrm{df}=$ number of frequency classes -3 .

${ }^{\mathrm{b}}$ The LRS resulting from the inclusion of a single aggregation parameter is tested by treating $\sqrt{\mathrm{LRS}}$ as a standardized normal deviate.

\section{A. Hettipola}

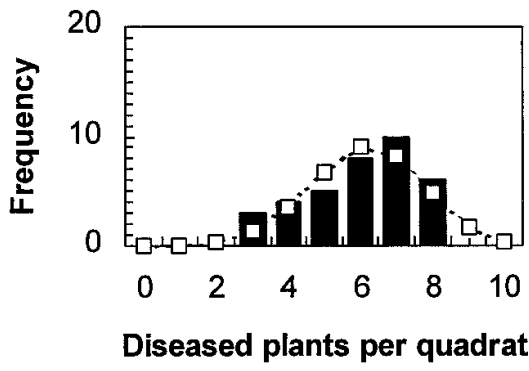

C. Devasarana

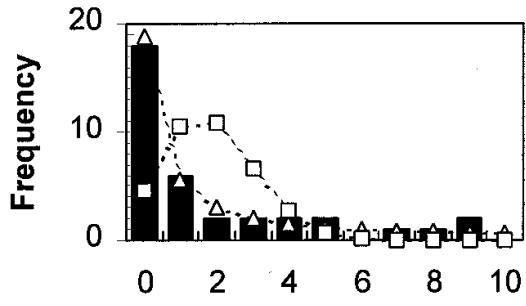

Diseased plants per quadrat
B. Kobeigane

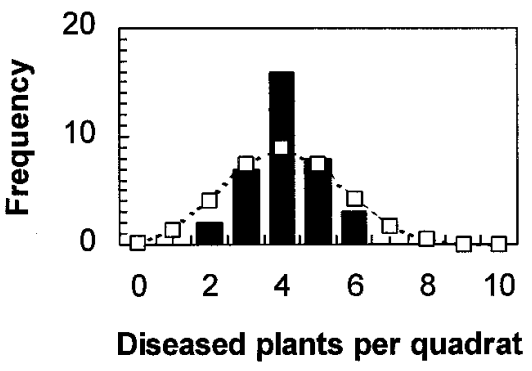

D. Aluwala

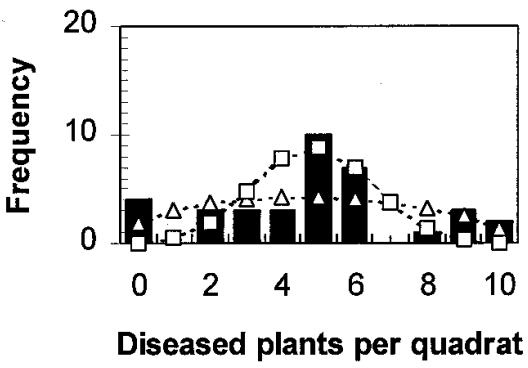

Fig. 2. Frequency distributions of disease incidence at four plantations. The observed data are shown as solid bars. Expected frequencies are shown as a frequency polygons: binomial distribution -- $\square--$; logistic-normal-binomial (LNB) distribution -- $\Delta--$. 
in the plots at Kuliyapitiya, Nittambuwa, and Attanagalla. However, the pattern in the plots at Wariyapola was random, or even underdispersed (i.e., deviations from randomness were in the direction of regularity).

In most cases, the results of the $\chi^{2}$ tests of goodness-of-fit were in agreement with the tests based on the likelihood ratio statistic. We regard the latter test as preferable, since it characterizes the improvement in fit (if any) offered by the LNB in a single test, and avoids the need for pooling of frequency classes with low expected values. Such pooling is always a rather arbitrary procedure. The same frequency classes will not necessarily be pooled for the separate $\chi^{2}$ tests on the two distributions; nor will there always be sufficient degrees of freedom (df) available, after pooling, to complete the tests (e.g., Attanagalla-Navadiga).

Figure 2 shows examples of observed frequency distributions of diseased plants per quadrat for data from selected plantations, together with fitted distributions. Figure 2A shows the data from Wariyapola-Hettipola, and the fitted binomial distribution, shown to be a good fit by both the $\chi^{2}$ and LRS tests (Table 2). The good fit of the observed data to the binomial distribution is indicative of a random pattern of diseased plants at the within-quadrat scale. Figure 2B shows the data from Wariyapola-Kobeigane, and the fitted binomial distribution. In this case, the fit of the binomial distribution is poor, and that of the LNB is worse (Table 2). Examination of Figure 2B shows that the observed data are underdispersed. There is a deficit of observed frequencies compared with the expected binomial frequencies in the tails of the distribution, and a corresponding ex- cess of observed frequencies in the center. That is to say, quadrats tend to have similar numbers of diseased plants. Since the LNB can only describe overdispersed data, the LRS could not be calculated (the same is true for the data from WariyapolaBingiriya).

Figure $2 \mathrm{C}$ shows the data from Kuliyapitiya-Devasarana, together with fitted binomial and LNB distributions. In this case, the fit of the binomial distribution is poor, and that of the LNB is a significant improvement (Table 2). There is an excess of observed frequencies over expected binomial frequencies in the tails of the distribution, and a corresponding deficit of observed frequencies in the center, typical of an aggregated pattern of diseased plants. The majority of the plots examined had this type of pattern (Table 2).

Finally, the data from NittambuwaAluwala, together with fitted binomial and LNB distributions, are shown in Figure 2D. In this case, the two goodness-of-fit tests are contradictory. The $\chi^{2}$ tests indicate that the fit of the binomial distribution is better than that of the LNB, while the LRS indicates a significant reduction in deviance on fitting the LNB, after first fitting the binomial distribution (Table 2). In fact, the frequency distribution of diseased plants per quadrat representing the observed data from the Aluwala plantation is rather complicated. Observed frequencies are large both in the tails of the distribution and in the center. The binomial distribution describes the central peak of the observed distribution better than the LNB, while the LNB describes better the tails of the observed distribution.

Analysis of the data according to their factor structure. Table 3 shows the results

Table 3. Analysis of deviance for the data from each village

\begin{tabular}{|c|c|c|c|c|c|}
\hline Model (equation) & Deviance & df & LRS & df & $P^{a}$ \\
\hline \multicolumn{6}{|c|}{ District - Kurunegala; Village - Wariyapola } \\
\hline Linear logistic (equation 1) & 212.45 & 143 & & & \\
\hline Linear logistic (equation 2) & 123.66 & 140 & 88.97 & 3 & $<0.001$ \\
\hline \multicolumn{6}{|c|}{ District - Kurunegala; Village - Kuliyapitiya } \\
\hline Linear logistic (equation 1) & 541.24 & 143 & & & \\
\hline Linear logistic (equation 2) & 519.55 & 140 & 21.69 & 3 & $<0.001$ \\
\hline LNB (equation 3) & 336.23 & 139 & 183.31 & 1 & $<0.001$ \\
\hline LNB (equation 4) & $321.98^{b}$ & 136 & 14.25 & 3 & 0.003 \\
\hline \multicolumn{6}{|c|}{ District - Gampaha; Village - Nittambuwa } \\
\hline Linear logistic (equation 1) & 527.75 & 143 & & & \\
\hline Linear logistic (equation 2) & 457.52 & 140 & 70.23 & 3 & $<0.001$ \\
\hline LNB (equation 3) & 355.15 & 139 & 122.37 & 1 & $<0.001$ \\
\hline LNB (equation 4) & $328.01^{\mathrm{b}}$ & 136 & 7.15 & 3 & 0.067 \\
\hline \multicolumn{6}{|c|}{ District - Gampaha; Village - Attanagalla } \\
\hline Linear logistic (equation 1) & 442.65 & 143 & & & \\
\hline Linear logistic (equation 2) & 345.09 & 140 & 96.56 & 3 & $<0.001$ \\
\hline LNB (equation 3) & 281.56 & 139 & 63.53 & 1 & $<0.001$ \\
\hline LNB (equation 4) & $273.55^{\mathrm{b}}$ & 136 & 8.01 & 3 & 0.046 \\
\hline
\end{tabular}

${ }^{a}$ In most cases, the logistic-normal-binomial (LNB) is regarded as having an asymptotic $\chi^{2}$ distribution for the purpose of significance testing. The exception is that the LRS resulting from the inclusion of a single aggregation parameter into a linear logistic model is not tested as a value of $\chi^{2}$, but by treating $\sqrt{\mathrm{LRS}}$ as a standardized normal deviate.

${ }^{b}$ Although the residual deviance remains high relative to the $\mathrm{df}$, this deviance will not necessarily have a $\chi^{2}$ distribution, so it is not possible to say whether or not there is another source of aggregation in the data (6). of fitting (where possible) the models represented by equations 1 to 4 , sequentially, to the data set for each village. On fitting the model represented by equation 1 , the resulting estimates were:

Wariyapola: $\hat{\eta}=0.125(\mathrm{SE}=0.0528)$;

Kuliyapitiya: $\hat{\eta}=-1.073(\mathrm{SE}=0.0605)$;

Nittambuwa: $\hat{\eta}=-0.647(\mathrm{SE}=0.0555)$;

Attanagalla: $\hat{\eta}=-0.942(\mathrm{SE}=0.0587)$.

The corresponding fitted probabilities, which are estimates of overall mean disease incidence at each village, were Wariyapola, $\hat{p}=0.53$; Kuliyapitiya, $\hat{p}=0.25$; Nittambuwa, $\hat{p}=0.34$; and Attanagalla, $\hat{p}=$ 0.28 .

In all cases, there was a large reduction in deviance when the model represented by equation 2 was fitted, after first fitting that represented by equation 1 . This is indicative of differences in mean incidence among plots, caused by either or both of the factors under analysis in each case. For the data from Wariyapola, neither of the models represented by equations 3 or 4 could be fitted. The fact that the residual deviance (123.6) on fitting the model represented by equation 2 was, in this case, less than its df (Table 3) reflects the random (or even slightly underdispersed) pattern of diseased plants in plots at Wariyapola. The analyses presented below for these data are based on the model represented by equation 2 .

For the data from Kuliyapitiya, Nittambuwa, and Attanagalla, there was a large reduction in deviance when the model represented by equation 3 (containing a single aggregation parameter, common to all plots) was fitted, after fitting that represented by equation 2 . There was a further, but smaller, reduction in deviance on fitting the model represented by equation 4 (containing separate aggregation parameters, reflecting the factor structure of the data), after fitting the model represented by equation 3. This reflects the aggregated pattern of diseased plants in plots at Kuliyapitiya, Nittambuwa, and Attanagalla. The analyses presented below for the data from plantations at these villages are all based on the model represented by equation 4 . The case for using the model based on equation 3 , or for using different models for different villages, is arguable. However, for data with such a simple factor structure, difficulties in calculating and interpreting the heterogeneity factors do not arise, and we simply opted for the model that provided the lowest residual deviance as a basis for estimating parameters and their standard errors.

Table 4 shows parameter estimates and their standard errors based either on the model represented by equation 2 (for Wariyapola) or on the model represented by equation 4 (for Kuliyapitiya, Nittambuwa, and Attanagalla). Briefly, we note that the largest effect of pesticide application was at Wariyapola, where all the 
plantations were in their first year of cultivation, but where mean disease incidence was the highest among the four villages. At Kuliyapitiya and Nittambuwa, disease incidence was greater in the 4-year-old than in the 1-year-old plantations. At Attanagalla, there was a large increase in disease incidence with year of cultivation in cv. Kew, but not in cv. Murici. Table 5 shows aggregation parameter estimates and their standard errors based on the model represented by equation 4, for Kuliyapitiya, Nittambuwa, and Attanagalla. The effect of including an aggregation parameter in the statistical model is to inflate the standard errors of parameter estimates, and of the differences between them, in comparison with standard errors based on the model represented by equation 2. The standard errors based on equation 4 (for Kuliyapitiya, Nittambuwa, and Attanagalla, where its adoption was appropriate) were, on average, $160 \%$ larger than the standard errors that resulted if equation 2 was (erroneously) used as a basis for the analysis of the data from Kuliyapitiya, Nittambuwa, and Attanagalla (the erroneous standard errors are not shown).

Table 4. Parameter estimates and standard errors after fitting either the model represented by equation 2 (Wariyapola) or the model represented by equation 4 (Kuliyapitiya, Nittambuwa, and Attanagalla) to the data from each village

\begin{tabular}{lccc}
\hline Model terma $^{\mathbf{a}}$ & Estimate & Standard error & $\boldsymbol{P}^{\mathbf{b}}$ \\
\hline District - Kurunegala; Village - Wariyapola & & \\
$C_{0}$ & 0.795 & 0.114 & $<0.001$ \\
+fertilizer & -0.331 & 0.156 & 0.035 \\
+pesticide & -1.166 & 0.156 & $<0.001$ \\
Interaction (residual) & 0.354 & 0.218 & 0.105 \\
District - Kurunegala; Village - Kuliyapitiya & & \\
$C_{0}$ & -2.932 & 0.602 & $<0.001$ \\
Year 4 of cultivation & 1.883 & 0.638 & 0.003 \\
+pesticide & 1.035 & 0.719 & 0.15 \\
Interaction (residual) & -0.918 & 0.782 & 0.24 \\
District - Gampaha; Village - Nittambuwa & & \\
Co & -1.104 & 0.193 & $<0.001$ \\
Year 4 of cultivation & 1.011 & 0.305 & 0.001 \\
+pesticide & -0.792 & 0.420 & 0.46 \\
Interaction (residual) & 0.388 & 0.523 & \\
District - Gampaha; Village - Attanagalla & & $<0.001$ \\
Co & -0.859 & 0.198 & 0.45 \\
Year 4 of cultivation & -0.240 & 0.321 & $<0.001$ \\
cv. Kew & -1.980 & 0.452 & $<001$ \\
Interaction (residual) & 2.637 & 0.537 & \\
\hline
\end{tabular}

${ }^{a}$ EGRET sets the estimates corresponding to the first level of each factor to zero and provides an estimate of the difference in response between the two levels of each factor and the standard error of that difference.

${ }^{\mathrm{b}}$ EGRET tests the significance of estimated parameters by reference to the standard normal distribution. These tests provide useful guidance on the importance of parameters, but should not be regarded as providing exact $P$ values.

Table 5. Aggregation parameter estimates and standard errors after fitting the model represented by equation 4 to the data from Kuliyapitiya, Nittambuwa, and Attanagalla villages

\begin{tabular}{lccc}
\hline Model term $^{\mathbf{a}}$ & Estimate & Standard error & $\boldsymbol{P}^{\mathbf{b}}$ \\
\hline District - Kurunegala; Village - Kuliyapitiya & & \\
$\gamma_{0}$ & 2.491 & 0.480 & $<0.001$ \\
Year 4 of cultivation & -1.536 & 0.524 & 0.003 \\
+pesticide & -0.747 & 0.580 & 0.20 \\
Interaction (residual) & 0.867 & 0.656 & 0.19 \\
District - Gampaha; Village - Nittambuwa & & \\
$\gamma_{0}$ & 0.813 & 0.207 & $<0.001$ \\
Year 4 of cultivation & 0.394 & 0.321 & 0.22 \\
+pesticide & 0.989 & 0.482 & 0.040 \\
Interaction (residual) & -1.220 & 0.581 & 0.036 \\
District - Gampaha; Village - Attanagalla & & \\
$\gamma_{0}$ & 0.891 & 0.209 & $<0.001$ \\
Year 4 of cultivation & 0.331 & 0.325 & 0.31 \\
cv. Kew & 0.483 & 0.450 & 0.28 \\
Interaction (residual) & -1.182 & 0.543 & 0.029 \\
\hline
\end{tabular}

a $E G R E T$ sets the estimates corresponding to the first level of each factor to zero and provides an estimate of the difference in response between the two levels of each factor and the standard error of that difference.

${ }^{\mathrm{b}}$ EGRET tests the significance of estimated parameters by reference to the standard normal distribution. These tests provide useful guidance on the importance of parameters, but should not be regarded as providing exact $P$ values.

\section{DISCUSSION}

The analysis of frequency distributions of diseased plants per quadrat shows that pineapple mealybug wilt disease tends to be aggregated, although some exceptions to this were also observed. Given the welldocumented, though as yet not fully-understood relationship between mealybugs and the disease, this is not surprising. Although there are no studies we are aware of that specifically relate to the spatial patterns of populations of the particular mealybugs associated with mealybug wilt of pineapple, the dispersal behavior of scale insects in general suggests that such patterns are likely to be aggregated (20).

The LNB distribution has been used both to describe aggregation in the frequency distributions of diseased plants per quadrat, and as a basis for statistical significance testing of effects. In fact, these two applications amount to the same thing. Taking the data from Kurunegala-Kuliyapitiya as an example, the total reduction in deviance achieved by fitting the LNB to the data from each plantation, after first fitting the binomial distribution, is $90.08+$ $20.38+58.90+28.21=197.57$ (Table 2$)$. The total reduction in deviance achieved by fitting the models represented by equations 3 and 4 in succession, after first fitting equation 2 , is $183.31+14.25=197.56$ (Table 3). Tables 2 and 3 both provide analyses of within-plot variability, using different parameterizations. Tables 4 and 5 give parameter estimates for the analysis as shown in Table 3. However, parameter estimates for the analysis as shown in Table 2 can also be derived from Tables 4 and 5, as follows:

$$
\begin{aligned}
& \hat{\eta}_{11}=\hat{C}_{0}, \hat{\gamma}_{11}=\hat{\gamma}_{0} ; \\
& \hat{\eta}_{21}=\hat{C}_{0}+\hat{A}_{2}, \hat{\gamma}_{21}=\hat{\gamma}_{0}+\hat{\gamma}_{A 2} ; \\
& \hat{\eta}_{12}=\hat{C}_{0}+\hat{B}_{2}, \hat{\gamma}_{12}=\hat{\gamma}_{0}+\hat{\gamma}_{B 2} ; \\
& \hat{\eta}_{22}=\hat{C}_{0}+\hat{A}_{2}+\hat{B}_{2}+(\hat{A B})_{22}, \\
& \hat{\gamma}_{22}=\hat{\gamma}_{0}+\hat{\gamma}_{A 2}+\hat{\gamma}_{B 2}+\hat{\gamma}_{(A B) 22} .
\end{aligned}
$$

For example, we again use the data from Kurunegala-Kuliyapitiya. Factor $A$ is "year of cultivation," with levels "1 year" $(i=1)$ and "4 years" ( $i=2)$. Factor $B$ is "use of pesticide," with levels "pesticide not applied" $(j=1)$ and "pesticide applied" $(j=$ 2). Then:

Devasarana: $\hat{\eta}_{11}=-2.932, \hat{\gamma}_{11}=2.491$

(the corresponding distribution is shown in Figure 2C);

Munumaldeniya: $\hat{\eta}_{21}=-2.932+1.883$

$=-1.049, \hat{\gamma}_{21}=2.491-1.536=0.955$;

Akkarawatta: $\hat{\eta}_{12}=-2.932+1.035$

$=-1.897, \hat{\gamma}_{12}=2.491-0.747=1.744$;

Mukalanyaya: $\hat{\eta}_{22}=-2.932+1.883$

$+1.035-0.918=-0.932, \hat{\gamma}_{22}=2.491$

$-1.536-0.747+0.867=1.075$.

In each case, $\hat{\eta}_{i j}$ and $\hat{\gamma}_{i j}$ are parameter estimates for the LNB distribution fitted to the frequency distribution of diseased plants per quadrat at a plantation. The same calculations can be made for other planta- 
tions where the data exhibited aggregation.

We note that when an evaluation of measures aimed at mealybug wilt disease aggregated management is the main objective, a more detailed examination of the appropriate terms to include in the linear predictor than has been carried out here is likely to be required. Once an appropriate description of the dispersion characteristics of a data set has been obtained, we can (in the case of a $2^{2}$ factorial arrangement, as above) fit a sequence of models for the main effects, as follows:

$$
\begin{aligned}
& \operatorname{logit}(p)=C_{0} ; \\
& \operatorname{logit}\left(p_{i}\right)=C_{0}+A_{i} ; \\
& \operatorname{logit}\left(p_{j}\right)=C_{0}+B_{j} ; \\
& \operatorname{logit}\left(p_{i j}\right)=C_{0}+A_{i}+B_{j} ; \\
& \operatorname{logit}\left(p_{i j}\right)=C_{0}+A_{i}+B_{j}+(A B)_{i j} .
\end{aligned}
$$

The likelihood ratio statistic can be used as a basis for deciding which of these models is appropriate for the calculation of parameter estimates and their standard errors.

The data presented in this article do not describe disease progress. However, the same methodology that has been described above can be used to fit disease progress curves where disease incidence data have been collected over, say, a number of seasons (e.g., 14). Instead of a relationship between disease incidence and the levels of one or more quantitative or qualitative factors, as above, a relationship between incidence and time (i.e., a continuous independent variable) is modeled. Use of the methodology described in this article to describe disease progress curves for incidence data has some advantages over the alternative of least squares regression analysis, in which a normal distribution is assumed for (transformed) incidence data at each time, and weights are calculated (to account for the fact that binary data do not have constant variance). Instead, a binomial or an LNB distribution (as appropriate) is assumed for incidence, rather than a normal distribution, and spatial heterogeneity is incorporated directly, where necessary, through the estimated aggregation parameter. As with the analysis of experimental data with a factor structure, the outcome is an analysis in which the calculation of parameter estimates and their standard errors takes into account the binary (and aggregated, where necessary) nature of disease incidence data. The advantages of the procedure outlined are greatest when the number of observations of incidence at each time is small (say, fewer than 30).
When incidence data are collected, in experiments and surveys, by recording the number of affected plants out of the total number in quadrats, we emphasize the importance of first arriving at an appropriate description of the pattern of disease incidence if the estimated standard errors (and so, the tests of statistical significance of parameter estimates) are to be valid. Once the most important factors affecting the spread of disease in time and space have been identified in this way, there is a basis for the development and calibration of a risk algorithm (29). Many risk factors associated with mealybug wilt pineapple have been identified (22), but at present, most of this information is qualitative rather than quantitative. Given the apparent intractability of the mealybug wilt problem, we suggest that the use of the methodology outlined in this article to quantify a risk algorithm is, alongside continuing studies of its etiology and epidemiology, a worthwhile objective for those involved in the management of this complicated disease.

\section{ACKNOWLEDGMENT}

The authors acknowledge the financial support of the British Council.

\section{LITERATURE CITED}

1. Anderson, D. 1988. Some models for overdispersed binomial data. Aust. J. Stat. 30:125-148.

2. Campbell, C. L., and Madden, L. V. 1990. Introduction to Plant Disease Epidemiology. John Wiley \& Sons, New York.

3. Carter, W. 1945. Some etiological aspects of mealybug wilt. Phytopathology 35:305-315.

4. Carter, W. 1956. Notes on some mealybugs (Coccidae) of economic importance in Ceylon. FAO Plant Prot. Bull. 4:49-52.

5. Cochran, W. G. 1936. The statistical analysis of field counts of diseased plants. Suppl. J. Royal Stat. Soc. 3:49-67.

6. Collett, D. 1991. Modelling Binary Data. Chapman \& Hall, London.

7. Department of Agriculture, Sri Lanka. 1993. Pineapple cultivation. Department of Agriculture, Sri Lanka. (in Sinhalese.)

8. Fernando, H. E. 1956. Pineapple and cacao mealy-bugs of economic importance in Ceylon. Trop. Agric. 62:132-141

9. German, T. L., Ullman, D. E., and Gunasinghe, U. B. 1992. Mealybug wilt of pineapple. Adv. Dis. Vector Res. 9:241-259.

10. Gunasinghe, U. B., and German, T. L. 1986. Association of virus particles with mealybugwilt of pineapple. (Abstr.) Phytopathology 76:1073.

11. Gunasinghe, U. B., and German, T. L. 1987. Further characterization of virus associated with mealybug-wilt of pineapple. (Abstr.) Phytopathology 77:1776

12. Gunasinghe, U. B., and German, T. L. 1988. Detection of viral RNA in mealybugs associated with mealybug-wilt of pineapple. (Abstr.)
Phytopathology 78:1584.

13. Gunasinghe, U. B., and German, T. L. 1989. Purification and partial characterization of a virus from pineapple. Phytopathology 79:1337-1341.

14. Habili, N., and Nutter, F. W., Jr. 1997. Temporal and spatial analysis of grapevine leafrollassociated virus 3 in Pinot Noir grapevines in Australia. Plant Dis. 81:625-628.

15. Hu, J. S., Sether, D. M., Liu, X. P., Wang, M., Zee, F., and Ullman, D. E. 1997. Use of a tissue blotting immunoassay to examine the distribution of pineapple closterovirus in $\mathrm{Ha}-$ waii. Plant Dis. 81:1150-1154.

16. Hu, J. S., Sether, D. M., and Ullman, D. E. 1996. Detection of pineapple closterovirus in pineapple plants and mealybugs using monoclonal antibodies. Plant Pathol. 45:829-836.

17. Hughes, G., Munkvold, G. P., and Samita, S. Application of the logistic-normal-binomial distribution to the analysis of Eutypa dieback disease incidence data. Int. J. Pest Manage. 44:35-42.

18. McCullagh, P., and Nelder, J. A. 1989. Generalized Linear Models. 2nd ed. Chapman \& Hall, London.

19. Mowat, W. P., and Dawson, S. 1987. Detection and identification of plant viruses by ELISA using crude sap extracts and unfractionated antisera. J. Virol. Methods 15:233247.

20. Nestel, D., Cohen, H., Saphir, N., Klein, M., and Mendel, Z. 1995. Spatial distribution of scale insects: Comparative study using Taylor's power law. Environ. Entomol. 24:506512.

21. Petty, G. J. 1985. The Pineapple Mealybug. Farming in South Africa H.15/1985.

22. Rohrbach, K. G., Beardsley, J. W., German, T. L., Reimer, N. J., and Sanford, W. G. 1988 Mealybug wilt, mealybugs, and ants on pineapple. Plant Dis. 72:558-565.

23. Sether, D. M., and Hu, J. S. 1997. Transmission of pineapple closterovirus (PCV) by two species of mealybug. Phytopathology 87:S88.

24. Singh, S. J., and Sastry, K. S. M. 1974. Wilt of pineapple - a new virus disease in India. Ind. Phytopathol. 27:298-303.

25. Thomson, K. G., Dietzgen, R. G., Thomas, J. E., and Teakle, D. S. 1996. Detection of pineapple bacilliform virus using the polymerase chain reaction. Ann. Appl. Biol. 129:57-69.

26. Ullman, D. E., German, T. L., Gunasinghe, U. B., and Ebesu, R. H. 1989. Serology of a closteroviruslike particle associated with mealybug wilt of pineapple. Phytopathology 79:1341-1345

27. Ullman, D. E., German, T. L., McIntosh, C. E., and Williams, D. D. F. 1991. Effect of heat treatment on a closteroviruslike particle associated with mealybug wilt of pineapple. Plant Dis. 75:859-861.

28. Wakman, W., Teakle, D. S., Thomas, J. E., and Dietzgen, R. G. 1995. Presence of a clostero-like virus and a bacilliform virus in pineapple plants in Australia. Aust. J. Agric. Res. 46:947-958.

29. Yuen, J., Twengström, E., and Sigvald, R. 1996. Calibration and verification of risk algorithms using logistic regression. Eur. J. Plant Pathol. 102:847-854. 